\title{
The Acceptance of Mobile Health Application for Older People in Indonesia
}

\author{
Shinta Happy Yustiari* \\ Faculty of Administrative Sciences \\ Brawijaya University \\ Malang, Indonesia \\ *shintahappyyustiari@gmail.com
}

\begin{abstract}
The higher percentage of cell phone usage amid the elderly people in Indonesia has unblocked the opportunity to benefit the health services online during the New Normal. In spite of cell phones consumption as well as learning the possible benefit of it to improve the healthcare services, the usage and acceptance of such technology amongst the older people is significantly low. The fact that less studies have been conducted to explore and acknowledge the elderly's perspective toward the acceptance of $\mathrm{m}$-health application services. This is the first study to combine UTAUT and TAM models to predict the BI (behavioral intention) to use m-health application in Indonesia. This research aims to find the key factors that effects the older people's acceptance of the $m$-health application. An online survey method with quantitative approach was used by questionnaire in Google document platform due to the pandemic of Covid-19. Data collection was performed by using the questionnaire sent to around 200 participants $(93 \%$ confidence level and $7 \%$ margin of error according to Slovin) whose age 50 years and above residing in 5 big cities in Indonesia. Data analysis was using the second generation multivariate tools (SEM) and analyzed by AMOS software. The findings show that PU and PEOU significantly influenced the elderly's intention to use m-health application, with the positive relationship between SI and BI. SI indicated the highest predictor following PEOU to behavioral intention amongst the other constructs. Therefore, in order to enhance the awareness and acceptance on $\mathbf{m}$-health services, it is necessary to target the productive family members as the agent of change. It is better that $\mathrm{m}$-health to be easy to use in order to attract the elderly people to use it.
\end{abstract}

Keywords-m-health application, older people

\section{INTRODUCTION}

Internationally, Indonesia rank the fifth-largest in the world on the number of elderly population (https://ageingasia.org) due to an increased life expectancy and a decrease in birth rates [1]. During a period of nearly five decades (1971-2019), the percentage of Indonesia's elderly population has approximately doubled. In 2019 , the elderly people reached $9.60 \%$ or around 25.66 million people. It shows that Indonesia is transitioning towards the ageing population due to the population aged over 60 years reaches above $7 \%$. It will become a country whose aging population structure if it is more than $10 \%$ of the total population. This phenomenon is a reflection of the increasing life expectancy on the Indonesian population. If it is balanced with the elderly ability to be independent, have good health quality, and do not become the burden on society, then the aging population will indirectly have a positive effect on national development.

The existence of the ageing population is spread both in urban and rural areas, in which the elderly who live in urban are higher than in rural areas $(52.80 \%$ versus $47.20 \%)$. The percentage of elderly in Indonesia is dominated by young elderly (age group of 60-69 yo) whose percentage reaches $63.82 \%$, the rest are middle elderly (age group of $70-79$ yo) of $27.68 \%$ and late elderly (age group of $80+$ yo) amounting to $8.50 \%$ as can be seen in Figures 1 and 2 [2].

Amid numerous aged users, the older people is more susceptible to chronic diseases, physical and mental incapacities [3]. The occurrence of chronic conditions that usually found in the ageing population demands for the improvement in both the quality and variety of health care services being offered [1]. Whereas, the Indonesian government has addressed the issues of older people's wellbeing with the National Plan of Action for Older Person Welfare Guidelines, which is designed to increase access to primary health care, encourage a healthy diet and physical activity, increase early detection of risk factors to health such as cholesterol, and increase referral services in geriatric clinics and hospitals (https://ageingasia.org).

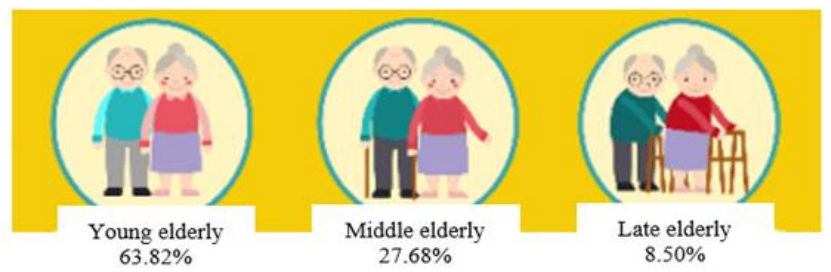

Fig. 1. Elderly age group. 


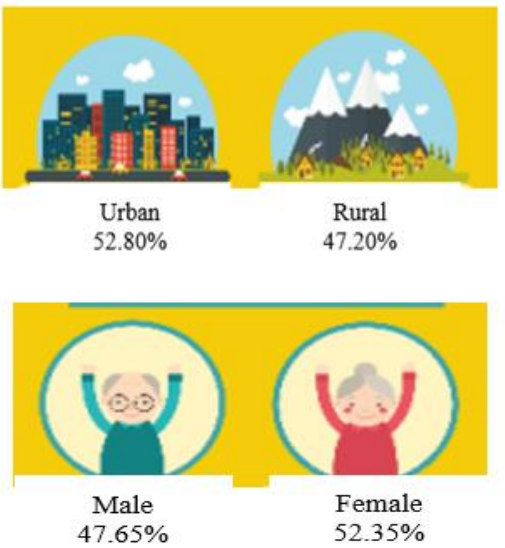

Fig. 2. Elderly sex and residence setting. Source: BPS [2].

In current years, m-health has expanded more attractiveness in developing countries where the possible benefits of m-health are recognized by many governments and have incorporated it in order to fulfill the sustainable development goals (SDGs) as the part of their health system goals [4,5]. M-health can reduce cost, save time, provide better access, and increase the interaction between patients, nurses and doctors as well as provide a faster means to send messages regarding the diseases and health [6]. It also offers broader access, more convenience, and may deliver the private and harmless means of obtaining the key answers for highly confidential health problems [7].

M-health services can be used to manage diseases effectively and expand the quality of life for the elder people. Elderly people with chronic disease have to meet frequently with the health professionals to manage their care appropriately [8]. Unfortunately, the difficulty arises when the elderly people had to meet with doctors regularly due to their physical disabilities [9]. Generally, m-health can be assessed through mobile phone, so that the increased in mobile phone users is expected to have positive impact to m-health adoption.

The higher percentage (43.08) of cell phone usage amid the elderly people in Indonesia has unblocked the opportunity to benefit the health services online during the New Normal. As, elderly people mostly suffers different diseases and needs to visit the healthcare provider regularly. It is rather tough for them, during the pandemic. Since the health protocol had to be implemented during the pandemic such as time limitation for visiting the health providers. Some health services are shifting to online mode (especially patient registration and physician appointment). Thus, the older people is gradually exposed to m-health and had to adjust their behavior toward the ICT. The latest survey on the information technology access among the elderly people through mobile phone in Indonesia is presented below (See Table 1):
TABLE I. IT AND COMMUNICATION ACCESS AMONG THE ELDERLY PEOPLE

\begin{tabular}{|l|l|}
\hline Characteristic & Total Elderly \\
\hline Total using mobile phone & $\mathbf{4 3 . 0 8}$ \\
\hline Residence setting & \\
\hline Urban & 49.05 \\
\hline Rural Gender & 36.41 \\
\hline \multicolumn{1}{|c|}{ Age group } & \\
\hline Male & 51.81 \\
\hline Female & 35.14 \\
\hline Young elderly (60-69 yo) & 51.52 \\
\hline Middle elderly (70-79 yo) & 32.18 \\
\hline Late elderly + 80 yo & 15.28 \\
\hline \multicolumn{2}{|c|}{ Source: Susenas [10]. }
\end{tabular}

The survey presents that mobile phone usage for IT and communication access is more likely to be affected by the residence setting than gender. The young elderly becomes the most age group to benefit mobile phone [10]. While a study on the ICT (internet) adoption found it was affected by the age, education, and income [11]. In term of m-health acceptance, previous studies recorded that age have significant impact on end users' acceptance of e-health even in rural setting [12] with significantly low acceptance, particularly in developing countries [13].

Less studies have been conducted to explore and acknowledge the elderly's perspective toward the acceptance of m-health application services. Earlier studies highlight the age factor to have significant impact on ICT (internet) adoption and m-health acceptance, especially the young elderly. With the low acceptance on m-health amongst the elderly, this research seeks to acknowledge the factors affecting the older people's behavior intention to accept $\mathrm{m}$-health application. The findings will be useful for the government's policy makers and health implementers to apply the precise approach to boost the elderly's acceptance on m-health.

\section{MATERIALS AND METHODS}

\section{A. Theoretical Framework and Hypothesis}

This study presented the integrated model of UTAUT (Unified Theory of Acceptance and Use of Technology) and (TAM) Technology Acceptance Model. TAM is the foremost theory in m-health acceptance. The current literature reviews showed that TAM has been developed to be a prominent model in understanding the behavioral predictors toward potential acceptance or rejection of the technology [14]. The UTAUT was derived of TAM [15]. The UTAUT model has been verified broadly since being introduced in various segments. It potentials to be a great means to analyze users' acceptance of health technology [16]. Behavioral intention (BI) to use constitutes the last measured construct in UTAUT model. It is defined as "a measure of the strength of one's intention to perform a specified behavior". BI is influenced by four main constructs among others: Performance expectancy (PE), Effort expectancy (EE), Social influence (SI), and Facilitating 
conditions (FC) [17]. Behavioral intention indicates to willingness of users to use or not an IS. The more intention of individual engages into behavioral, the more success the project it is $[18,19]$. BI and the actual use behavior are strongly associated. The actual use behavior can be predicted by the behavioral intention [20]. In the study, with mixture of TAM and UTAUT constructs hereunder aims to understand the predictor of elderly's intention in using the m-health services [17] (See Figure 3).

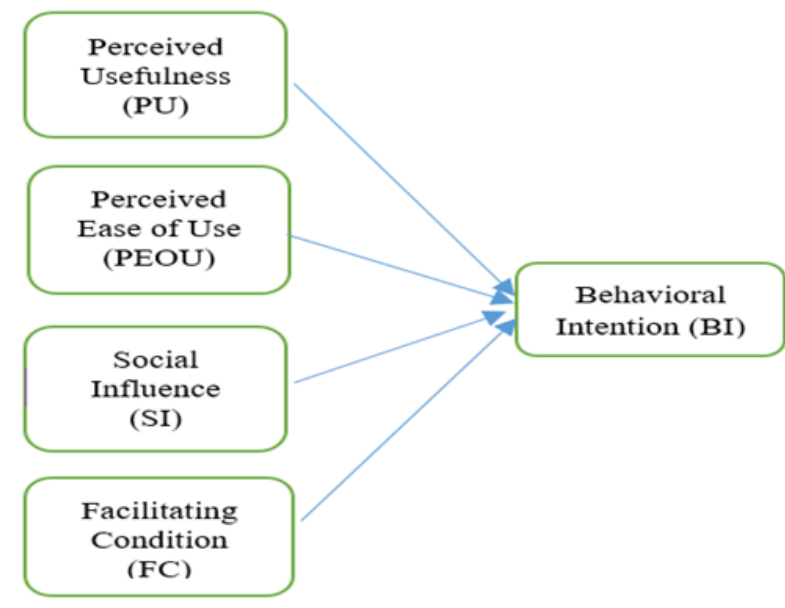

Fig. 3. Research model.

1) Perceived Usefulness (PU): It states that perceived usefulness (PU) will influence the individual's behavioral intention to use the system. PU is defined as the "usefulness" to which a person believes that his or her job performance will enhance by the system usage [19]. In the context of m-health, researchers found that $\mathrm{PU}$ is a vital factor which determines the adoption of $m$-health since users consider its benefits [6]. Hence, it is postulated the following hypothesis:

H1: Perceived usefulness positively effects the elderly's intention in using the $\mathrm{m}$-health services.

2) Perceived Ease Of Use (PEOU): It is established to which users perceive that the usage of a specific system shall be ease and may be free [19]. Perceived ease of use (PEOU) establish to which users perceive that the usage of a specific system shall be ease and may be free [19]. Some previous studies have found PEOU to have direct relationship to attitude [21,22]. Hence, it is postulated the following hypothesis:

H2: Perceived ease of use positively effects the elderly's intention in using the m-health services.

3) Social Influence (SI): This is the degree to which an individual recognizes the importance of other people's perspectives when decided that he or she had to use the new system [15]. Pan and Jordan-Marsh [23] revealed that SI was a significant predictor of technology use intention among older adults. Social influence as predictors of behavioral intention in the acceptance of 3G services in Taiwan [24] and towards consumer's acceptances of mobile advertising [25]. Hence, it is postulated the following hypothesis:

H3: Social Influence positively effects the elderly's intention in using the m-health services.

4) Facilitating Condition ( $F C$ ): It is defined as the degree to which an individual trusts that the existence of organizational and technical infrastructure to support the system usage [15]. Facilitating condition positively influences the behavioral intention and the smartphones usage for health services [26] and directly effects behavioral intention on technology usage [27]. Therefore, it is assumed the following hypothesis:

H4: Facilitating Condition positively effects the elderly's intention in using the m-health services.

\section{B. Questionnaire Development and Data Collection}

Data collection used was survey method with quantitative approach. The survey questionnaire consisted of two parts. The first part entails of 10 questions from demographic factors based on the respondents' demographic characteristics such as gender, educational background, occupation, age, monthly income, etc. The second section consists of 13 questions to capture on the indicators of each construct. The PU and PEOU constructs were adapted from Davis [19] and Taylor and Todd [28]. The SI, FC and BI were adopted from Venkatesh et al. [15]. Each SI, FC, and PU were measured with three indicators. Each PEOU and BI were measured with two indicators. The demographic characteristics in the first part was the structured questions with the provided answers. All items in the second part were measured using a 7-point Likert scale, started from $1=$ strongly disagree, to $7=$ strongly agree. The questionnaire was distributed online in Bahasa Indonesia through the google document application. A pretest survey was conducted prior to the actual one to enhance the questions. The survey sheet circulated to respondents including the aim of study, information, and consent form. Population size originated of total elderly population $(0.01 \%$ x 25.66 millions $)$ with $93 \%$ confidence level and $7 \%$ margin of error according to Slovin. A total of 142 clean questionnaires were collected from 200 questionnaires distributed. Six incomplete questionnaires were excluded $(3 \%)$. The response rate reached $0.71 \%$.

The structural equation modeling (SEM) was benefited to evaluate the interdependence among constructs and validate the research model. As according to Byrne (2012) the SEM has the vital aspects to express the causal procedures of concentrate through a series of structural equations; and to display the structural relations pictorially. Firstly, responses to the survey were recorded, exported in a spreadsheet (Microsoft Excel), and transferred to SPSS, and AMOS software for in depth analysis. 


\section{RESULTS}

\section{A. Validity and Reliability}

Prior to hypothesis testing, the constructs' reliability and validity should be measured. The reliability was assessed by using the composite reliability (CR) whose value of 0.70 or more $(\geq 0.7)$ to be acceptable. This in order to avoid a lack of internal consistency or reliability ( $\mathrm{CR} \leq 0.60$ according to Hair and Hult [29]). Validity measurement will be evaluated by Variance Extracted (VE) whose value had to be $\geq 0.50$. Table 2 shows that all the constructs have composite reliability $(\mathrm{CR}) \geq$ 0.7 . All the constructs have VE values $\geq 0.50$. It represents the data had the good reliability and validity.

TABLE II. VALIDITY AND RELIABILITY OF CONSTRUCTS

\begin{tabular}{|c|c|c|c|}
\hline Construct & Indicator & VE & $\mathbf{C R}$ \\
\hline \multirow{3}{*}{$\begin{array}{l}\text { Perceived Usefulness } \\
\text { (PU) }\end{array}$} & PU1 & \multirow{3}{*}{0.605} & \multirow{3}{*}{0.864} \\
\hline & PU2 & & \\
\hline & PU3 & & \\
\hline \multirow{2}{*}{$\begin{array}{l}\text { Perceived Easy of } \\
\text { Use (PEOU) }\end{array}$} & PEOU1 & \multirow{2}{*}{0.799} & \multirow{2}{*}{0.888} \\
\hline & PEOU2 & & \\
\hline \multirow{2}{*}{$\begin{array}{l}\text { Behavioral Intention } \\
(\mathrm{BI})\end{array}$} & BI1 & \multirow{2}{*}{0.554} & \multirow{2}{*}{0.713} \\
\hline & $\mathrm{BI} 2$ & & \\
\hline \multirow{2}{*}{ Social Influence (SI) } & SI1 & \multirow{2}{*}{0.527} & \multirow{2}{*}{0.782} \\
\hline & SI2 & & \\
\hline \multirow{3}{*}{$\begin{array}{l}\text { Facilitating Condition } \\
\text { (FC) }\end{array}$} & FC1 & \multirow{3}{*}{0.523} & \multirow{3}{*}{0.706} \\
\hline & $\mathrm{FC} 2$ & & \\
\hline & FC3 & & \\
\hline
\end{tabular}

\section{B. Goodness of Fit Model}

Measurement of Goodness of Fit Model based on Table 3 shows that the CMIN/DF, RMSEA, GFI and CFI presented the Goodness of Fit. According to Arbuckle and Wothke [30], Chi Square / DF and RMSEA are the best criteria referred as the indicator of the goodness of fit model. The Chi Square / DF value must less than or similar to $2(\leq 2.00)$, and RMSEA value must less than or similar to $0.08(\leq 0.08)$. Therefore, the CMIN / DF and RMSEA values had to meet the cut off value. The SEM model herein is suitable and can be proceed for further analysis.

TABLE III. MEASUREMENT OF GOODNESS OF FIT MODEL

\begin{tabular}{|l|l|l|l|}
\hline $\begin{array}{c}\text { Goodness of } \\
\text { Fit Index }\end{array}$ & $\begin{array}{c}\text { Criteria } \\
\text { (Cut-off value })\end{array}$ & $\begin{array}{c}\text { Indicator } \\
\text { Value }\end{array}$ & Conclusion \\
\hline Chi-Square & less & 79.658 & \multirow{2}{*}{ Poor Fit } \\
\hline P-value & $\geq 0.05$ & 0.002 & \\
\hline CMIN/DF & $\leq 2.00$ & 1.695 & Goodness of Fit \\
\hline RMSEA & $\leq 0.08$ & 0.070 & Goodness of Fit \\
\hline GFI & $\geq 0.90$ & 0.921 & Goodness of Fit \\
\hline AGFI & $\geq 0.90$ & 0.847 & Marginal Fit \\
\hline TLI & $\geq 0.95$ & 0.947 & Marginal Fit \\
\hline CFI & $\geq 0.95$ & 0.968 & Goodness of Fit \\
\hline
\end{tabular}

Source: primary data processed

\section{Confirmatory Factor Analysis}

Confirmatory Factor Analysis (CFA) measures each research construct with indicator whose highest loading factor indicates the strongest denomination and significant of the measured construct (if the $\mathrm{P}$-value $<0.05$, or declared fix).

TABLE IV. CFA OF CONSTRUCT

\begin{tabular}{|l|l|l|l|}
\hline \multicolumn{1}{|c|}{ Construct } & Indicator & Loading Factor & P-value \\
\hline \multirow{2}{*}{$\begin{array}{l}\text { Perceived } \\
\text { Usefulness (PU) }\end{array}$} & PU1 & 0.712 & 0.000 \\
\cline { 2 - 4 } & PU2 & 0.674 & 0.000 \\
\cline { 2 - 4 } & PU3 & 0.932 & Fix \\
\hline \multirow{2}{*}{$\begin{array}{l}\text { Perceived Easy of } \\
\text { Use (PEOU) }\end{array}$} & PEOU1 & 0.878 & 0.000 \\
\cline { 2 - 4 } $\begin{array}{l}\text { Behavioral } \\
\text { Intention (BI) }\end{array}$ & PEOU2 & 0.997 & Fix \\
\hline \multirow{2}{*}{$\begin{array}{l}\text { Social Influence } \\
\text { (SI) }\end{array}$} & BI2 & 0.766 & Fix \\
\hline \multirow{2}{*}{$\begin{array}{l}\text { Facilitating } \\
\text { Condition (FC) }\end{array}$} & SI2 & 0.770 & 0.000 \\
\cline { 2 - 4 } & FC1 & 0.959 & Fix \\
\cline { 2 - 4 } & FC2 & 0.487 & 0.000 \\
\cline { 2 - 4 } & FC3 & 0.998 & Fix \\
\hline
\end{tabular}

Based on table 4, the study found that PU3 is the strongest measure of PU (loading factor 0.932) when respondents found that $\mathrm{m}$-health be helpful in accessing the medical services that they want. The PEOU2 is the strongest measure of PEOU (loading factor 0.997) when the m-health is convenience to be used. SI1 is the strongest measure of SI (loading factor 0.959) with the fact that most Indonesians downloaded m-health may influence the respondents' intention to use the application. FC2 is the strongest measure of FC (loading factor 0.998) provided by the convenience in using $\mathrm{m}$-health to check the payment status. BI2 is the strongest measure of BI (loading factor 0.766) in term of all the constructs determinant fulfilled, then respondents will use the $\mathrm{m}$-health services regularly in the future.

\section{The Structural Model}

The path correlation among the constructs was evaluated by the structural research model. The study tests the relation among the constructs by path coefficient and $\mathrm{p}$ value. The study found that PU (structural coefficient $=0.420, \mathrm{p}=0.000$ ), PEOU (structural coefficient $=0.441, \mathrm{p}=0.000$ ), SI (structural coefficient $=0.475, p=0.000)$, had significantly effect on elderly's intention to use m-health. Hence, H1, H2, and $\mathrm{H} 3$ were confirmed. Unfortunately, FC (structural coefficient = $0.010, p=0.890$ ) had not significantly effect on the older people's intention. So, H4 was not supported (Table 5). 
TABLE V. STRUCTURAL MODEL: DIRECT INFLUENCE

\begin{tabular}{|l|l|l|l|l|}
\hline No & \multicolumn{1}{|c|}{$\begin{array}{c}\text { The Relation Between } \\
\text { Constructs }\end{array}$} & Coefficient & $\begin{array}{c}\text { P- } \\
\text { value }\end{array}$ & Remark \\
\hline 1. & $\begin{array}{l}\text { Perceived Usefulness (PU) to } \\
\text { Behavioral Intention (BI) }\end{array}$ & 0.420 & 0.000 & Significant \\
\hline 2. & $\begin{array}{l}\text { Perceived Easy of Use } \\
\text { (PEOU) to Behavioral } \\
\text { Intention (BI) }\end{array}$ & 0.441 & 0.000 & Significant \\
\hline 3. & $\begin{array}{l}\text { Social Influence (SI) to } \\
\text { Behavioral Intention (BI) }\end{array}$ & 0.475 & 0.000 & Significant \\
\hline 4. & $\begin{array}{l}\text { Facilitating Condition (FC) } \\
\text { to Behavioral Intention (BI) }\end{array}$ & 0.010 & 0.890 & $\begin{array}{l}\text { Non- } \\
\text { significant }\end{array}$ \\
\hline
\end{tabular}

\section{DISCUSSION}

This is the first study to combine UTAUT and TAM models to predict the BI (behavioral intention) to use m-health application in Indonesia. The findings presented that the model is a decent predictive of elderly's intention to adopt m-health application. Regarding TAM-related constructs, the findings show that PU and PEOU significantly influenced the elderly's intention to use m-health application. PEOU has the higher coefficient that PU, indicated the easiness of use will be the factor to influence the elderly's intention to use m-health. This are in line with previous studies. PU is the most vital determinant of $\mathrm{m}$-health adoption and PEOU has direct relationship to attitude $[6,21,22]$. The UTAUT constructs, it is found the positive relationship between SI and BI to use mhealth services, with SI the highest predictors amongst the other constructs. According to Pan and Jordan-Marsh [23], SI was a significant predictor of technology use intention among older adults. Unfortunately, this research did not address any substantial relationship between facilitating condition and elderly's behavioral intention to use of m-health application. The finding presents the opposite to several studies before that approve the direct impact / positive relationship on behavioral intention and use of technology. The fact reflects that most of elderly in Indonesia are dependent to family support for living. This presented by the increased of dependency ratio from 14.49 in 2018 to 15.01 in 2019 according to BPS [2].

The increased number of elderly people effects the provision of health services while the productive family members also must provide care for them. This proved that FC may be insignificant to influence the elderly's intention due to their dependency. Whether or not the government campaign boost to promote and the officers to encourage the use of $\mathrm{m}$ health services, they still count on the adult children or younger family members to decide their intention. These findings addressed the key aspects to influence the older people's usage intention to m-health. Thus, this must be considered in the development of policies and strategies regarding m-health services especially in developing countries. The facilitating factors must be highlighted prior to the implementation of $\mathrm{m}$ health program. In addition, for the smooth improvement of $\mathrm{m}$ health services, appropriate training should be provided to healthcare professionals. Raising the campaign of using $\mathrm{m}$ health services is necessary. This is the perfect time due to New Normal era when most services are shifting to online to adhere the health protocol. The strategy is to enhance the awareness on m-health services by targeting the productive family members. They will be the agent of change to support the elderly people in using the $\mathrm{m}$-health services especially those who do not have any experience with $\mathrm{m}$-health services before.

\section{CONCLUSION}

During the New Normal era, the support of m-health services is very useful for older people to reduce the administration complexities to obtain their intended health services while adhere to the Covid-19 safety protocol. In order to gradually change their ICT behavior, raising the campaign of using m-health services to them is necessary. The best approach is by targeting the social inner networking as the agent of change. They are the younger family members living with them. This due to fact that most elderly are dependent to their family support and will note the influence of their inner network. Besides, m-health must be designed to be easy to use for elderly. These findings will be the useful input for the government and policy makers, as well as the mobile phone company as the infrastructure providers.

\section{REFERENCES}

[1] R. Hoque and G. Sorwar, "Understanding factors influencing the adoption of mHealth by the elderly: An extension of the UTAUT model," International journal of medical informatics, vol. 101, pp. 7584, 2017.

[2] BPS, Statistik Penduduk Lanjut Usia 2019.

[3] Z.N. Kabir, The emerging elderly population in Bangladesh: Aspects of their health and social situation. Department of Clinical Neuroscience, Occupational Therapy and Elderly Care Research (NEUROTEC), Division of Geriatric Medicine, Karolinska Institutet, 2001.

[4] A. Beratarrechea, A.G. Lee, J.M. Willner, E. Jahangir, A. Ciapponi, and A. Rubinstein, "The impact of mobile health interventions on chronic disease outcomes in developing countries: A systematic review," Telemedicine and E-Health, vol. 20, no. (1), pp. 75-82, 2014.

[5] L. Wallis, P. Blessing, M. Dalwai, and S.D. Shin, "Integrating mHealth at point of care in low-and middle-income settings: the system perspective," Global health action, vol. 10, no. (sup3), p. 1327686, 2017.

[6] M.R. Hoque, "An empirical study of mHealth adoption in a developing country: the moderating effect of gender concern," BMC medical informatics and decision making, vol. 16, no. (1), pp. 1-10, 2016.

[7] Z. Deng, X. Mo, and S. Liu, "Comparison of the middle-aged and older users' adoption of mobile health services in China," International Journal of Medical Informatics, vol. 83, no. (3), pp. 210-224, 2014.

[8] N. Aldrich and W.F. Benson, "Disaster preparedness and the chronic disease nedds of vulnerable older adults," Preventing Chronic Disease: Public Health Research, Practice, and Policy, pp. 1-7, 2008.

[9] N.S. Wickramasinghe, A.M. Fadlalla, E. Geisler, and J.L. Schaffer, "A framework for assessing e-health preparedness," Int. J Elect Health, vol. 1, pp. 316-334, 2005.

[10] Survei Sosial Ekonomi Nasional (SUSENAS) Kor 2019.

[11] C. Porter and N. Donthu, "Using the Technology Acceptance Model to explain how attitudes determine internet usage," Journal of Business Research, vol. 59, pp. 999-1007, 2006.

[12] N. Hossain, F. Yokota, N. Sultana, and A. Ahmed, "Factors influencing rural end-users' acceptance of e-health in developing countries: a study 
on portable health clinic in bangladesh," Telemedicine and e-Health, vol. 25, no. (3), pp. 221-229, 2019.

[13] G.A.A. Quaosar, M.R. Hoque, and Y. Bao, "Investigating factors affecting elderly's intention to use m-health services: an empirical study," Telemedicine and e-Health, vol. 24, no. (4), pp. 309-314, 2018.

[14] N. Marangunit and A. Granit, "Technology acceptance model: a literature review from 1986 to 2013," Univers. Access Inf. Soc, vol. 14, pp. 81-95, 2014.

[15] V. Venkatesh, M.G. Morris, B. Gordon, E.D. Davis, and Davis, "User acceptance of information technology: toward a unified view," MIS Quarterly, vol. 27, no. (3), pp. 425-478, 2003.

[16] A.J.E. De Veer, J.M. Peeters, R.E. Brabers, F.G. Rademakers, and A.L. Francke, "Determinants of the intention to use e-Health by community dwelling older people," BMC Health Serv. Res. March, vol. 1, p. 103, 2015.

[17] M. Cimperman, M.M. Brenčič, and P. Trkman, "Analyzing older users' home telehealth services acceptance behavior-applying an Extended UTAUT model," International journal of medical informatics, vol. 90, pp. 22-31, 2016.

[18] I. Ajzen, "The theory of planned behavior," organizational behavior and human decision process, vol. 50, no. (2), pp. 179-211, 1991.

[19] F.D. Davis, "Perceived usefulness, perceived ease of use, and user acceptance of information technology," MIS Quarterly, pp. 319-340, 1989.

[20] A. Bhattacherjee and N. Hikmet, "Re-conceptualizing organizational support and its effect on information technology usage: Evidence from the health care sector," J Comp Inform Syst, vol. 48, pp. 69-76, 2008.

[21] O. Al Hujran, M. Al-Debei, A.T. Chatfield, and M. Migdadi, "The imperative of influencing citizen attitude toward e-government adoption and use," Computers in Human Behavior, vol. 53 (December), pp. 189203, 2015.
[22] M.M. Mostafa and A. El-Masry, "Citizens as consumers: Profiling egovernment services' users in Egypt via data mining techniques," International Journal of Information Management, vol. 33, no. (4), pp. 627-641, 2013.

[23] S. Pan and M. Jordan-Marsh, "Internet use intention and adoption among Chinese older adults: From the expanded technology acceptance model perspective," Computers in Human Behavior, vol. 26, pp. 1111$1119,2010$.

[24] Y.L. Wu, Y.H. Tao, and P.C. Yang, "Using UTAUT to explore the behavior of 3G mobile communication users," In 2007 IEEE international conference on industrial engineering and engineering management, pp. 199-203, 2007. IEEE.

[25] D. He and Y. Lu, "Consumers perceptions and acceptances towards mobile advertising: An empirical study in China," In 2007 International Conference on Wireless Communications, Networking and Mobile Computing, pp. 3775-3778, 2007. IEEE.

[26] W. Boontarig, W. Chutimaskul, V. Chongsuphajaisiddhi, and B. Papasratorn, "Factors influencing the Thai elderly intention to use smartphone for e-Health services," In 2012 IEEE symposium on humanities, science and engineering research, pp. 479-483, 2012. IEEE.

[27] Y.Y. Mun, J.D. Jackson, J.S. Park, and J.C. Probst, "Understanding information technology acceptance by individual professionals: Toward an integrative view," Inform Manag, vol. 43, pp. 350-363, 2006.

[28] S. Taylor and P. Todd, "Decomposition and crossover effects in the theory of planned behavior: A study of consumer adoption intentions," International journal of research in marketing, vol. 12, no. (2), pp. 137$155,1995$.

[29] Jr. J.F. Hair and G.T.M. Hult, A primer on partial least squares structural equation modeling (PLS-SEM). Thousand Oaks, CA: Sage Publications, 2016.

[30] J. Arbuckle and W. Wothke, AMOS 4 user's reference guide. Chicago: Smallwaters Corporation, 1999. 